induce vomiting, which could then cause acute dilatation from hypokalaemia. Secondly, the hyperosmolar effect of introducing a relatively large amount of fluid and food into a stomach which has become used to less will cause dilatation.

Acute dilatation of the stomach is thus a recognized, if rare, complication of any patient suffering from anorexia nervosa who is beginning treatment. It seems that conservative management alone is adequate in the acute phase provided the condition is discovered before perforation of the stomach occurs. The mortality of uncomplicated gastric dilatation is low, but after perforation it is $80 \%$ (Evans, 1968).

We considered whether any medication the patients received before presentation might have caused the dilatation. One patient had been treated with diazepam and the other with chlorpromazine. We consulted Side Effects of Drugs (Meyler and Herxheimer, 1968) which made no reference to such effects after diazepam therapy. The phenothiazines have, however, on rare occasions been noted to cause a depression of gastric secretion leading to paralytic ileus in psychotic patients. This was noted in four out of 720 people studied. Since only one of our patients had received phenothiazines, however, we feel it is unlikely to have been a precipitating cause of presentation.

We thank Dr. N. C. Oswald and Mr. E. G. Tuckwell for permission to report these cases which were under their care and also Mr. W. M. Castleden for his comments and help.

\section{References}

Dragstedt, L. R., Montgomery, M. L., Ellis, J. C., and Matthews, W. R. (1931). Surgery, Gynecology and Obstetrics, 52, 1075.

Evans, D. S. (1968). British fournal of Surgery, 55, 940.

Markowski, B. (1947). British Medical fournal, $2,128$.

Meyler, L., and Herxheimer, A. (editors) (1968). Side Effects of Drugs, Vol. 6. Amsterdam, Excerpta Medica.

Russell, G. F. M. (1966). British Fournal of Psychiatry, 112, 203.

\title{
Titanium Cranioplasty
}

\section{S. GORDON, G. A. S. BLAIR}

British Medical fournal, 1974, 2, 478-481

\section{Summary}

The technique of repairing defects of the skull with titanium is described. The skull contour can be accurately reproduced. The technique is simpler than wiring or suturing methods. The material is inert, radiolucent, and rigid.

\section{Introduction}

One of the most conspicuous after effects of a depressed fracture of the skull or a penetrating missile injury is a disfiguring skull defect. Repair by cranioplasty is often needed. Frontal defects more than $2 \mathrm{~cm}$ in diameter are usually unsightly, and some cause discomfont, especially when the patient stoops. Larger defects leave the brain vulnerable to trauma, giving the patient a sense of insecurity.

A satisfactory cranioplasty should employ an onlay technique with a simple method of attaching the prosthesis to the skull. The material used should be inert in the tissues, radiolucent, easily and accurately shaped, capable of being adjusted at the time of insertion, and it should have sufficient mechanical strength to resist fracture or deformation under severe impact loading.

After the 1914-18 war autogenous bone was the material of choice for cranioplasty. But repair of a large defect requires a major operation to obtain the graft. Reproduction of the correct skull contour often proves difficult, and the patient often has more postoperative pain from the donor site than from the grafted area.

Some of the skull defects from the 1939-45 war were repaired with autopolymerized acrylic resin plates. At first they were preformed from a template or impression made at the finst operation. Spence (1954) described form-fioting plastic

\footnotetext{
Department of Neurosurgery, Royal Victoria Hospital, Belfast BT12 6BA

D. S. GORDON, M.CH., F.R.C.s., Consultant
}

Department of Dental Prosthetics, Dental School, Belfast BT12 6BA G. A. S. BLAIR, M.D.S., F.F.D., Senior Lecturer and Consultant cranioplasty in which the plastic was moulded into the defect during the hardening process. When the defeot is large, however, a smoothly contoured plate is difficult to shape and fit accurately.

Metals and alloys, including tantalum, titanium, stainless steel, and chrome-cobalt are not widely used because of the difficulty in forming the plate to the compound complex curvatures of the skull. Tantalum was used after the 1939-45 war (Woodhall and Spurling, 1947). It was shaped by a die/ counter die swaging technique or by hammering into a counter die (Lewin et al., 1948). Lewin and Gibson (1956) used tantalum to repair some of the skull defeots in British soldiers injured in Korea. The higher thermal conductivity of metals as compared with acrylic resin may limit their use for large plates in very hot climates (Spence, 1954.) For treating small skull defects plastic or metal plates or bone-grafting will usually prove satisfactory. The larger defect, however, poses special problems of contour and fixation which are difficult to solve by any of the available techniques.

In the civil disturbances in Northern Ireland over 900 people died between 1969 and 1973. In this type of urban guerilla warfare over $95 \%$ of penetrating injuries are gunshor wounds, many of them caused by high velocity bullets. The survivors usually have large skull defects, some with an area greater than $20 \mathrm{in}^{2}\left(129 \mathrm{~cm}^{2}\right)$.

We describe here how titanium has been used to repair these defects. The method combines accuracy with ease of insertion and is now used for skull defects of any size.

\section{Methods}

\section{INITIAL OPERATION}

Because of the risk of infection immediate cranioplasty is seldom advisable in patients with compound depressed skull fractures with brain laceration. The overlying skin is often severely lacerated and many wounds are heavily contaminated. Certain steps taken at the initial operation, however, will facilitate subsequent cranioplasty. A full-thickness skin cover for the defect and later for the prosthesis is essential. In missile wounds and depressed fractures caused by sharp objects the scalp laceration is often small and can be excised and sutured. A generous scalp flap is then cut about 2-3 cm beyond the limits of the skull fracture. This flap can be reflected 
again for the cranioplasty procedure. For frontal wounds a coronal flap may be preferable. When the scalp laceration is more extensive retraction of the wound edges gives sufficient exposure. Patients who have lost an area of scalp usually need skin advancement or a rotation scalp flap.

Apart from neurological damage the chief complication of a compound cranial wound is infection, leading to meningitis or brain abscess (Jefferson, 1919). Initial surgery is therefore directed towards the removal of foreign material and bone fragments. Intact skull is removed by rongeurs until normal dura mater is exposed around the brain wound; the resulting defect becomes considerably larger than seen on the initial $x$-ray pictures (figs. 1 and 2).

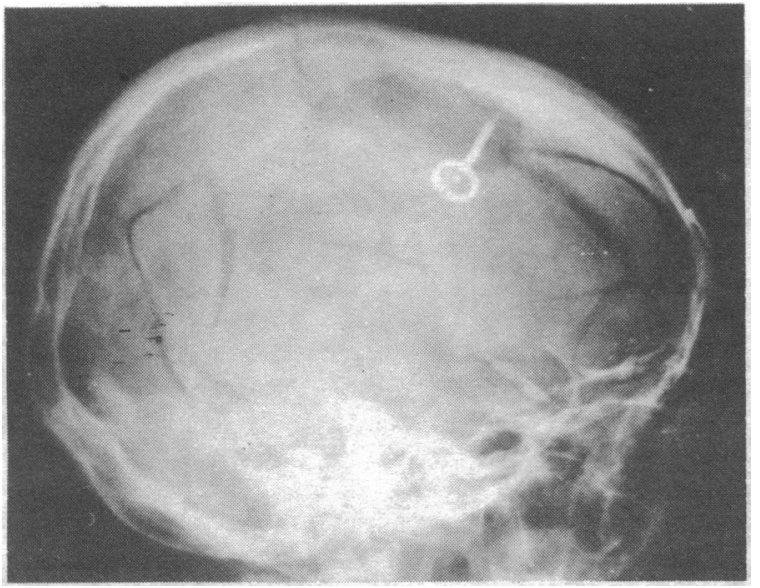

FIG. 1-Tangential high velocity bullet wound in parietal bone producing "gutter" fracture and widespread shattering of surrounding skull. Pressurerecording transducer has been inserted between skull and dura mater.

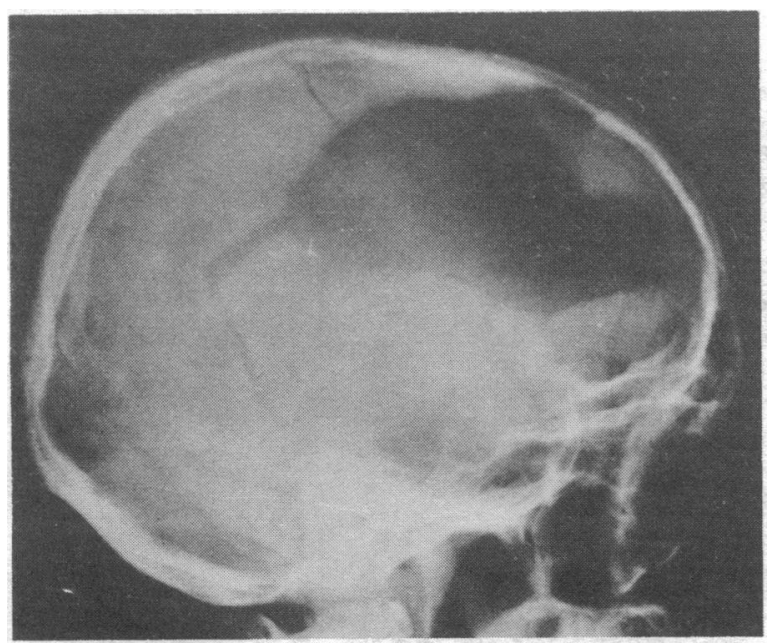

FIG. 2-Postoperative skull $x$-ray picture after debridement and removal of contaminated bone fragments. Area of skull defect is $17 \mathrm{in}^{2}\left(109 \mathrm{~cm}^{2}\right)$.

Accurate dural repair is necessary (Wallace and Meirowsky, 1960), and no complications arise provided early neurosurgical treatment has been instituted. Homografts of temporal fascia or pericranium are used if the dural odges cannot be apposed; even in large wounds fascia lata is seldom needed. These grafts have remained viable when inspected later at cranioplasty. The graft acts as a barrier between the subarachnoid and subgaleal spaces preventing inward spread of infection and outward flow of cerebrospinal fluid to form a fistula.

Dural closure, by restoring the normal anatomical layer, minimizes scarring between the brain and overlying scalp
(Penfield, 1927). Gillingham (1947) suggested that cerebral fungus formation occurred less often after dural closure. Restitution of the dural layer facilitates cranioplasty (Lewin and Gibson, 1956) as it provides an easy plane of cleavage to allow scalp reflection. When the dura has not been closed the overlying scalp will be found adherent either to the brain or the layer of false dura covering the brain. This layer is thin and during cranioplasty it may tear, allowing a collection of cerebrospinal fluid to form around the prosthesis.

After dural closure a template, cut from a soft malleable metal* to the shape of the defect and about $5 \mathrm{~mm}$ oversize, is moulded to the skull contour and is used later in the preparation of the titanium plate.

In larger defects an impression can be made using sterile dental alginate material. The impression records the bone contour around the edge of the defect and an accurate reproduction of the lesion can then be made in dental plaster. Finally, the skull thickness is measured to allow choice of an appropriate screw for fixation of the plate.

Some patients are referred from other hospitals and a template or impression may not have been prepared at the initial operation. An external impression technique is then used to record the shape and size of the defect through the skin. The scalp is shaved over the defect and about $3 \mathrm{~cm}$ bevond its periphery. An indelible pencil line is made on the scalp about $5 \mathrm{~mm}$ beyond the margin of the defect. The line represents the size and shape of the plate. Strips of soft malleable carding wax are placed on the scalp around the defeot which is then covered with dental alginate material to a depth of $2 \mathrm{~cm}$. Before the alginate gels, deep grooves are made on its exposed surface. After complete gelation a thick mixture of dental plaster of Paris is applied to the alginate, which acts as a backup material to prevent distortion. When the alginate is removed its deep surface will be found marked by the pencil line on the scalp.

\section{PREPARATION OF THE PLATE}

From the impression a dental plaster cast is made and built up to the required contour with dental wax (fig. 3). Using the shaped cast a die is prepared in dental stone which is then placed in a high pressure hydraulic forming chamber (fig. 4).

The plate which will cover the defect is made from titanium I.M.I. $115,0.024$ in $(0.61 \mathrm{~mm})$ thick. A titanium blank,

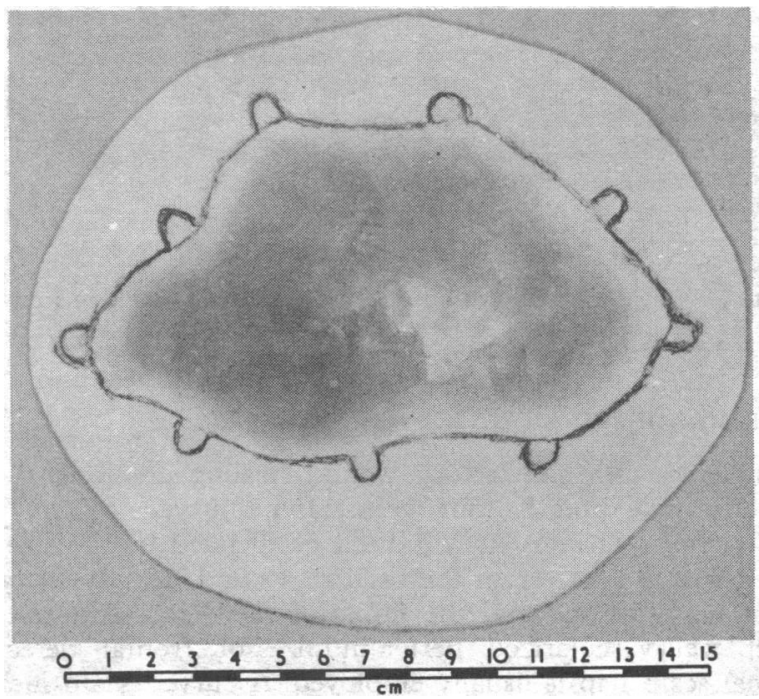

FIG. 3-Dental plaster cast built up to simulate skull contour. Peripheral projections mark where fixation screws will be applied.

*Ash's Metal, Amalgamated Dental Trade Distributors Limited. 


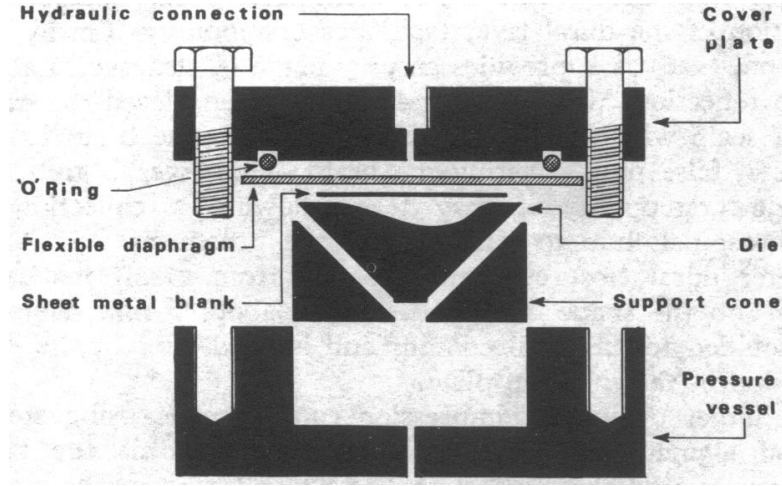

FIG. 4-Slow rate hydraulic forming chamber.

placed over the die and covered with a flexible neoprene rubber diaphragm, is clamped in position by bolting the cover plate to the pressure vessel. Fluid pressure, applied to the surface of the rubber diaphragm by a high pressure hydraulic pump, moulds the titanium sheet on to the surface of the die (Bahrani et al., 1965). After forming, the plate is cut to the exact size leaving a series of peripheral projections which are drilled to receive the retaining screws (fig. 5). Holes drilled over the surface of the plate allow fluid to escape from the small space between the dura mater and the plate; fibrous tissue can grow through the plate and promote the development of a thin vascularized fibrous covering which simulates pericranium. The finished plate is anodized to provide an enriched compact oxide surface layer (see Appendix).

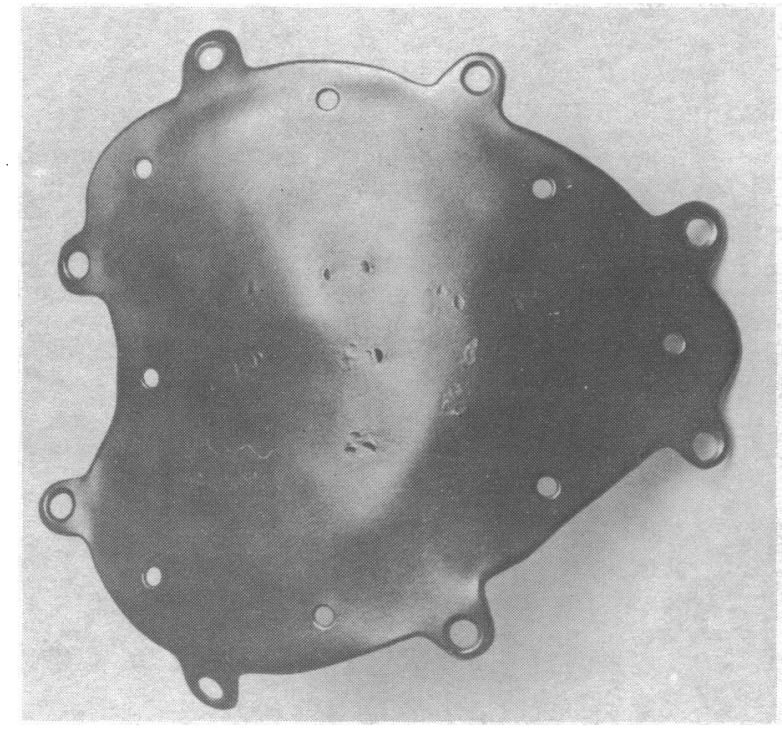

FIG. 5-Titanium plate with drilled projections for retaining screws.

\section{INSERTION OF THE PLATE}

In patients with satisfactory wound healing cranioplasty can be performed three or four weeks after injury.

The choice of incision will often be diotated by the size and position of the scar from the original wound. Ideally a cranioplasty scar runs beyond the limits of the defect and rests on intact well-vascularized pericranium. For frontal defects a coronal scalp flap is usually employed. A curved scalp incision round a straight scar introduces the risk of incision line necrosis. It is sometimes preferable, therefore, to reopen a wound which runs across the skull defect. A broad thin scar over the defect may require preliminary plastic revision. When the scalp has been reflected an incision is made through the pericranium or muscle surrounding the defect. The soft tissues are reflected away from the margin to allow the plate to sit on the bone. The plate is now placed in position to check its shape and contour. Minor alterations to the perforated projeotions on the edge of the plate can then be made with hawksbill pliers. If the skull thickness has not been recorded at the first operation a modified round no. 8 dental bur which projects $5 \mathrm{~mm}$ from the dental handpiece is used to make an exploratory hole. The bur should just penetrate the inner table of the skull. In most skulls a $6 \mathrm{~mm}$ or $7 \mathrm{~mm}$ bur will be needed. The appropriate titanium self-tapping screws* are inserted round the periphery of the plate at predetermined positions (fig. 6). The scalp is sutured; a vacuum drain remains under the scalp for 24 hours.

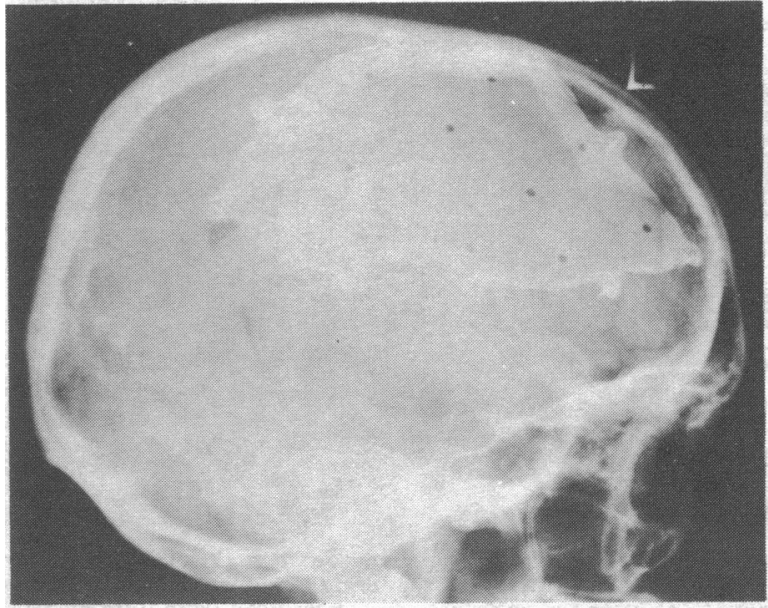

FIG. 6- $X$-ray picture of same skull as in figs. 1 and 2 after titanium cranioplasty. Metal clips and fracture lines can be seen through plate.

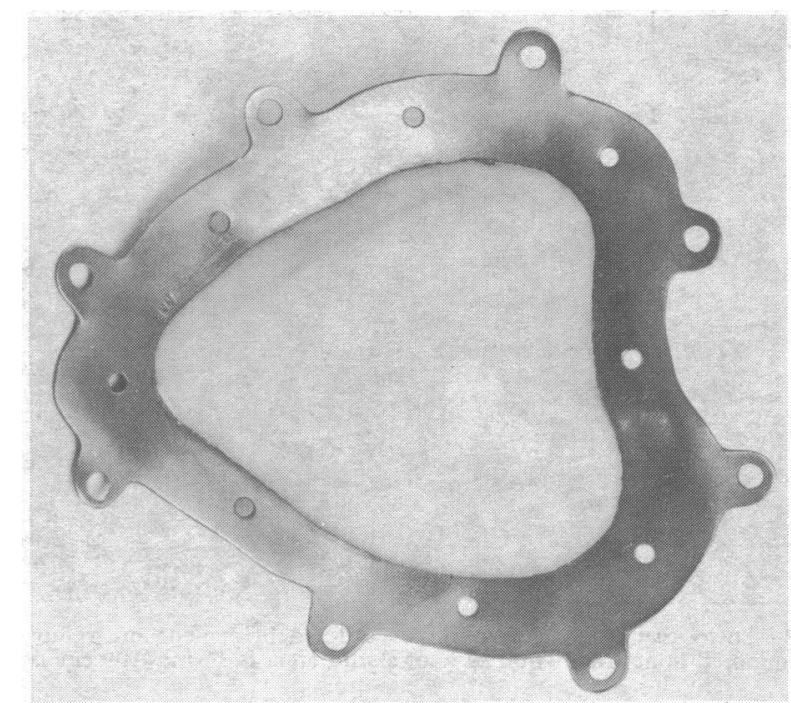

FIG. 7-Form-fitting cranial plate. An acrylic mass attached to deep surface of plate fills dead space between dura mater and plate.

\section{Discussion}

Twenty-five patients with large skull defects caused by gunshot or bomb explosion injuries have had titanium cranioplasty, and the method has proved to have several benefits.

Precision.-The skull contour can be accurately reproduced and minor adjustments are easily made.

*Titanium screw I.M.I. 325, JCH 342-18, 19, 20 Down Bros., England. 
Ease of Fixation.-Drilling the skull and inserting screws is technically simple and much easier than wiring or suturing methods, which involve dissection of the bone edge and the extradural space. The use of an onlay technique considerably reduces the operating time.

Good Tissue Acceptance.-Anodized titanium is an inert implant material. There is no reactive oedema of the scalp and no postoperative subgaleal effusion.

Dead Space.-Previous metal onlay techniques did not include provision for obliterating the dead space between the plate and the dura. When there is a large space a heat-cured acrylic resin mass can be processed to the tissue fitting surface of the plate (fig. 7).

Radiolucency.-An objection to most metallic plates is that they are radio-opaque. Titanium, however, is sufficiently radiolucent to allow radiological studies (see fig. 6).

Strength.-When titanium sheet is shaped to a formed contour it becomes rigid and will withstand considerable external force. As the plate is $0.5-1 \mathrm{~cm}$ "oversize," only an exceptional force would displace it inwards.

Lightness.-The density of titanium is low compared with that of other metals and alloys.
Sterilization.-Titanium plates and screws can be autoclaved. As most plastic materials need protection to prevent deformation due to stress relief on heating their sterility cannot be guaranteed.

\section{Appendix}

The anodizing solution is made up of $80 \%$ phosphoric acid, $10 \%$ sulphuric acid, and $10 \%$ water. The anode is titanium, voltage comes from a single phase rectified supply $0-120 \mathrm{~V}$, and the current is about $10 \mathrm{~A} / \mathrm{ft}^{2}$.

\section{References}

Bahrani, A. S., Blair, G. A. S., and Crossland, B. (1965). British Dental fournal, 118, 425.

Gillingham, F. J. (1947). British fournal of Surgery, War Surgery Supplement no. 1 , p. 80.

Jefferson, G. (1919). British Fournal of Surgery, 7, 262.

Lewin, W., and Gibson, R. M. (1956). British Fournal of Surgery, 43, 628. Lewin, W., Graham, M. P., and Northcroft, G. B. (1948). British fournal of Surgery, 36, 26

Penfield, W. (1927). Brain, 50, 409.

Spence, W. T. (1954). Fournal of Neurosurgery, 11, 219.
Wallace, P. B., and Meirowsky, A. M. (1960). Annals of Surgery, 151, 174. Woodhall, B., and Spurling, R. G. (1945). Annals of Surgery, 121, 649.

\section{MEDICAL MEMORANDA}

\section{Hepatorenal Failure with Self- initiated Intermittent Rifampicin Therapy}

\author{
D. L. ROTHWELL, D. E. RICHMOND
}

British Medical fournal, 1974, 2, 481-482

Continuous rifampicin therapy is considered to be relatively non-toxic. Nevertheless, complications associated with its intermittent administration have been reported (Campese et al., 1973; Kleinknecht, 1972; Poole et al., 1971; Girling et al., 1971; Aquinas et al., 1972). The symptoms include pyrexia, chills, arthralgia, jaundice, and acute renal failure. We report a case of combined hepatorenal failure in a patient who took rifampicin from time to time of her own accord.

\section{Case Report}

A 62-year-old European woman was admitted to hospital in September 1973 complaining of acute abdominal pain, nausea, vomiting, and chills. She was confused, but her history was later confirmed by her husband.

In April 1972 she was diagnosed as having active pulmonary tuberculosis. Three cachets of sodium aminosalicylate twice a day and rifampicin $450 \mathrm{mg}$ daily were prescribed. She took these regularly until August 1973 when she developed severe heartburn and stopped both. Six days later she took three tablets of rifampicin. After two hours she developed chills, nausea, and vomiting, which resolved after 24 hours but left her lethargic for two weeks, during which she took no rifampicin. A fortnight after her first intermittent dose she took three tablets of rifampicin and some hours later she

Department of Medicine, Auckland Hospital, New Zealand

D. L. ROTHWELL, M.B., CH.B., Registrar

D. E. RICHMOND, M.B., M.R.C.P., Senior Lecturer developed nausea amd malaise. Three days later she again took three tablets of rifampicin. This was rapidly followed by acute pain in the right loin, nausea, and vomiting. She had had severe dermatitis 39 years previously after a course of sulpha drugs. There was no preexisting renal or liver disease.

On admission she was jaundiced and had a temperature of $38^{\circ} \mathrm{C}$. No obvious abnormality was detected in the cardiovascular or respiratory system; the blood pressure was $140 / 80 \mathrm{mg} \mathrm{Hg}$. She was almost anuric and was confused. Blood values were: bilirubin 4.3 $\mathrm{mg} / 100 \mathrm{ml}$; Prothrombin time $60 \%$; alkaline phosphatase $165 \mathrm{IU}$; SGOT $1,450 \mathrm{IU} / \mathrm{ml}$; urea $106 \mathrm{mg} / 100 \mathrm{ml}$; creatinine $2.2 \mathrm{mg} / 100 \mathrm{ml}$; Hb $12.3 \mathrm{~g} / 100 \mathrm{ml}$; E.S.R. $15 \mathrm{~mm}$ in 1 hour (Westergren). Reticulocyte counts were $1.4 \%, 1.5 \%$, and $1.3 \%$ during the two weeks after admission. Urine microscopy showed white cells 13/high-power field, red blood cells 15/high-power field, no casts, and no protein. Nothing abnormal was seen on chest $x$-ray examination. Antistreptolysin- $\mathrm{O}$ antistreptokinase, antihyaluronidase titres, and serum complement were all normal. Tests for L.E. cells and antinuclear factor gave negative results. These findings indicated hepatocellular damage and early acute renal failure with an absence of haemolysis. Liver function returned to normal after five days but the patient remained anuric and became progressively uraemic. The pain disappeared rapidly and its cause was never explained. Peritoneal dialysis was performed on the seventh day. Renal biopsy was not performed because glomerulonephritis seemed an unlikely diagnosis and she was'treated as a case of acute tubular necrosis. Three days later she began a brisk diuresis and her renal function soon returned to normal.

\section{Comment}

Side effects of intermittent rifampicin therapy are well recognized (Aquinas et al., 1972). One of the more well-defined syndromes is an influenza-like illness with pain and shock similar to that described by the patient. It is not widely known that intermittent rifampicin therapy can cause acute renal and hepatic failure, though workers in Scandinavia and Hong Kong have described transient minor abnormalities of liver function near the start of treatment (Aquinas et al., 1972). The few reported cases of acute renal failure have occurred when an intermittent high dose of rifampicin has been deliberately prescribed. Acute tubular necrosis has been found on renal biopsy in two such patients (Aquinas et al., 1972; Campese, 